Case Study

\title{
Non-surgical improvement of cervical lordosis is possible in advanced spinal osteoarthritis: a $\mathrm{CBP}^{\circledR}$ case report
}

\author{
Miles O. Fortner ${ }^{1)}$, Paul A. OAKley ${ }^{2 *}$, Deed E. Harrison ${ }^{3)}$ \\ 1) Private Practice, USA \\ 2) Private Practice, Canada \\ 3) CBP NonProfit, Inc., USA
}

\begin{abstract}
Purpose] To present a case of the non-surgical improvement in cervical kyphosis in a patient with history of cervical spine trauma and advanced osteoarthritis. [Subject and Methods] A 38 year old male presented with a chief complaint of chronic neck pain that was not substantially relieved by recent previous traditional physiotherapy and chiropractic manipulation. The cervical radiograph demonstrated a cervical hypolordosis of $5^{\circ}$ as measured by the Harrison posterior tangent method from $\mathrm{C} 2-\mathrm{C} 7$. There was a $15^{\circ}$ kyphosis at $\mathrm{C} 4-\mathrm{C} 6$ with advanced degenerative changes consistent with previous spine trauma. The patient was treated by $\mathrm{CBP}^{\circledR}$ methods incorporating cervical extension traction, extension exercises, and spinal manipulation for 30 sessions over an 18 week period. [Results] After the treatment sessions, there was a substantial $\left(27^{\circ}\right)$ increase in global $\mathrm{C} 2-\mathrm{C} 7$ lordosis, and $5^{\circ}$ decrease in $\mathrm{C} 4-\mathrm{C} 6$ degenerative kyphosis corresponding to the reduction in neck pain and disability, and an improvement in overall health status as indicated on the SF-36 health questionnaire. [Conclusion] Although degenerative spondylosis of the cervical spine will have physical limitations to non-surgical correction, this case serves as an example that it is possible to reduce degenerative kyphosis and increase global cervical lordosis corresponding to health improvements in these patients.

Key words: Cervical kyphosis, Osteoarthritis, Extension traction
\end{abstract}

(This article was submitted Sep. 15, 2017, and was accepted Oct. 13, 2017)

\section{INTRODUCTION}

Cervical kyphotic deformity is a potentially disabling spinal condition ${ }^{1)}$. As with a normal cervical lordosis configuration $^{2)}$, the posterior structures bear two-thirds of the load, while the vertebral bodies and discs bear one-third of the load ${ }^{3)}$. Kyphosis causes an anterior shifting of the load axis and a potential wedge deformity of the vertebrae and discs ${ }^{1)}$. This creates a moment arm-induced forward flexion bending moment, creating a perpetual cycle of progressive kyphosis ${ }^{4}$.

Cervical kyphosis is associated with vertebral body stresses that are much larger, i.e. 6-10 $\times$ the stresses than the normal lordotic configuration which have been found to be uniform and minimal throughout the cervical vertebrae ${ }^{5)}$. The biomechanical over-stressing onto the vertebral bodies in cervical kyphosis provides the basis for the formation of osteoarthritic changes to the bony structures (including osteophytes) via Wolff's Law ${ }^{6,7}$ ).

We present a case of the non-surgical improvement of cervical kyphosis in a 38 year old with a history of cervical spine trauma and radiographic features of osteoarthritis.

*Corresponding author. Paul A. Oakley (E-mail: docoakley.icc@gmail.com) (C2018 The Society of Physical Therapy Science. Published by IPEC Inc. 
Table 1. Short form-36. Scores for initial (4-13-17) and follow-up assessments (5-18-17; 7-11-17).

\begin{tabular}{rccccccc}
\hline Date & $\begin{array}{c}\text { Health } \\
\text { perception }\end{array}$ & $\begin{array}{c}\text { Physical } \\
\text { functioning }\end{array}$ & $\begin{array}{c}\text { Role } \\
\text { physical }\end{array}$ & $\begin{array}{c}\text { Role } \\
\text { emotional }\end{array}$ & $\begin{array}{c}\text { Social } \\
\text { functioning }\end{array}$ & $\begin{array}{c}\text { Mental } \\
\text { health }\end{array}$ & $\begin{array}{c}\text { Bodily pain } \\
\text { Energy/Fatigue }\end{array}$ \\
\hline Normal & 72 & 84 & 81 & 81 & 83 & 75 & 75 \\
$4-13-17$ & 45 & 50 & 0 & 100 & 50 & 72 & 33 \\
$5-18-17$ & 70 & 50 & 25 & 100 & 75 & 76 & 61 \\
$7-11-17$ & 57 & 75 & 25 & 100 & 75 & 80 & 68 \\
\hline
\end{tabular}

\section{SUBJECT AND METHODS}

On 4-12-17, a 38 year old male presented with chronic neck pain. He reported two previous cervical spine injuries. First, he injured the cervical spine while performing a backflip off a 4-foot high structure and landed on his head compressing his spine. The very next day he suffered a whiplash event and lost consciousness while riding bareback on a bronco at a rodeo. The injured patient did not see a doctor or seek medical attention until years later.

The patient reported to have received traditional chiropractic and physical therapy treatments over the previous 3 years with only temporary relief. Upon assessment, the patient rated his neck pain to average $4 / 10$ ( $0=$ no pain; $10=$ worst pain ever). He reported blurry peripheral vision, pain in the outer portion of his left hand, upper back pain, low back pain when sleeping, running or with physical activities, low energy, diarrhea, and bilateral knee and hip pain.

The patient scored a $30 \%$ on the neck pain disability index questionnaire (NDI) ${ }^{8}$, and below normal on $7 / 8$ health indices on the 36-item physical and mental health questionnaire (SF-36; Table 1) ${ }^{9}$.

Visual posture analysis ${ }^{10}$ ) showed a right head translation posture $(-\mathrm{TxH})$ and an extended thoracic posture (-RzT). Cervical range of motion (ROM) was restricted and painful on cervical extension and limited in bilateral, lateral flexion; other ROMs were within normal limits (WNL). Cervical flexion strength was painful and rated as 4/5, the L4 dermatome was hyposensitive on the left. Deep tendon reflexes were normal. Positive orthopedic tests included Jacksons bilaterally, shoulder depression with radiation of pain on the right.

Cervical radiographs were taken and analyzed using the PostureRay system (Trinity, FL, USA). This system uses the Harrison posterior tangent method to measure sagittal images ${ }^{11,12)}$ and the modified Risser-Ferguson method to measure AP images ${ }^{12)}$. These methods are repeatable and reliable as is posture ${ }^{11-13)}$. The patient had a complete loss of cervical lordosis, having an absolute rotation angle (ARA) between $\mathrm{C} 2-\mathrm{C} 7$ of $-4.8^{\circ}$ (vs. $-31-42^{\circ}$ normal ${ }^{14}$, 15 ); negative indicates extension), with a mid-cervical kyphosis of $+15.1^{\circ}$ between $\mathrm{C} 4-\mathrm{C} 6$ (Fig. 1). There was minimal anterior head translation (AHT: $7.3 \mathrm{~mm}$ ), and an atlas plane line (APL) of $-18.8^{\circ}$ (vs. $24-29^{\circ}$ normal $^{14,16)}$ ). Severe degenerative changes involving vertebrae C4-C6, indicative of previous cervical spine injury was noted on the radiograph, consistent with the patient's history.

The patient was treated by Chiropractic BioPhysics ${ }^{\circledR}\left(\mathrm{CBP}^{\circledR}\right)$ technique ${ }^{17-19)}$ and the goal was to improve the cervical lordosis. CBP technique was created by Don Harrison in 1980 and incorporates mirror image ${ }^{\circledR}$ exercises, adjusting procedures, and traction methods to restore normal/ideal spine and posture. The patient was put on an initial care plan of 3 times a week 10 weeks.

'Pope 2-way' cervical extension traction was used (Fig. 2) ${ }^{19,20)}$. This involves a mid-neck forward pull while the head is in the extension position supported in an occiput-chin harness with a posterior-superior pull. Also a 'thoracic-flex traction body weight' (Circular Traction Supply Inc., Huntington Beach, CA, USA) was used to pre-stress the upper thoracic spine in kyphosis; this is to enhancing the stress on the cervical spine. Traction started at 8 minutes and progressed up to 20 minutes per session to achieve maximal disc and ligamentous creep ${ }^{21)}$.

Mirror image ${ }^{\circledR}$ cervical extension exercises were performed on the PowerPlate ${ }^{\circledR}$ (Northbrook, IL, USA) using a 'prolordotic' elastic resistance band (Circular Traction Supply Inc., Huntington Beach, CA, USA) (Fig. 3). Exercises were held for 5 seconds and performed for 6 minutes. The PowerPlate is a three-dimensional vibration platform that adds intensity to any exercise ${ }^{22)}$. The patient was also instructed to do 100 repetitions of the neck exercise at home on a daily basis and to use a cervical Denneroll $^{\mathrm{TM}}$ (Denneroll Spinal Orthotics, Wheeler Heights, NSW, Australia) for 10 minutes on the off-days to compliment the in-office treatments. The patient also received spiral manipulative therapy. The patient gave verbal and written consent for the publication of these results including all images and radiographs.

\section{RESULTS}

Follow-up pain and health questionnaires were given on 5-18-17 and 7-11-17. The patient scored a $26 \%$ and a $16 \%$ on the NDI on these two dates, and improved in 5/8, and in $4 / 8$ health indices on the SF-36 on these two dates (Table 1).

Follow-up assessment (8-6-17) revealed all previous positive orthopedic tests to be WNL, except that the cervical ROM was still limited presumably due to the osseous deformation of $\mathrm{C} 4-\mathrm{C} 7$ vertebral bodies. Grip strength improved 4 pounds of strength in each hand. The patient did report neck pain improved, being less severe and less often, but would rise to a 3/10 at worst. Overall the patient reported a complete resolution of blurry peripheral vision, a $90 \%$ improvement in diarrhea, an $80 \%$ 


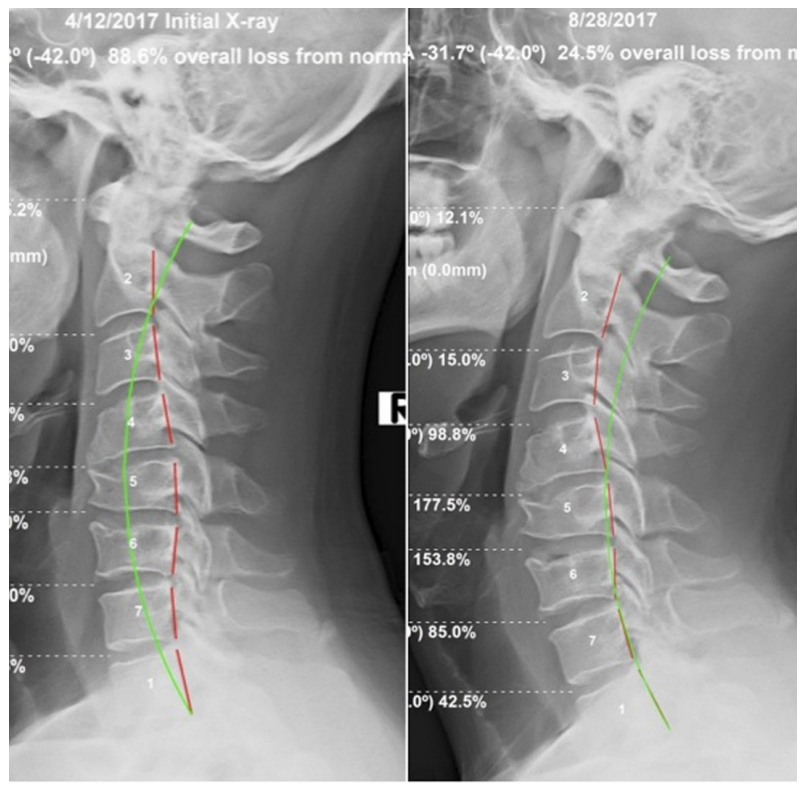

Fig. 1. Neutral standing lateral cervical radiographs.

Left: Initial taken on 4-12-17. Right: Follow-up taken 8-28-17. Green line represents ideal alignment; red line highlights posterior vertebral body margins. Note the Clay shoveler's fracture of spinous process of $\mathrm{C} 7$; severe degenerative changes to vertebral body's $\mathrm{C} 4-\mathrm{C} 7$ as well as the region's initial exaggerated kyphotic deformation indicative of previous trauma.

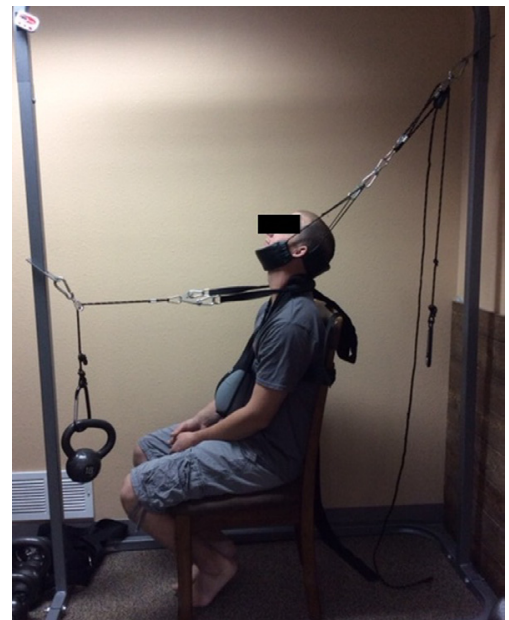

Fig. 2. Pope 2-way cervical extension traction.

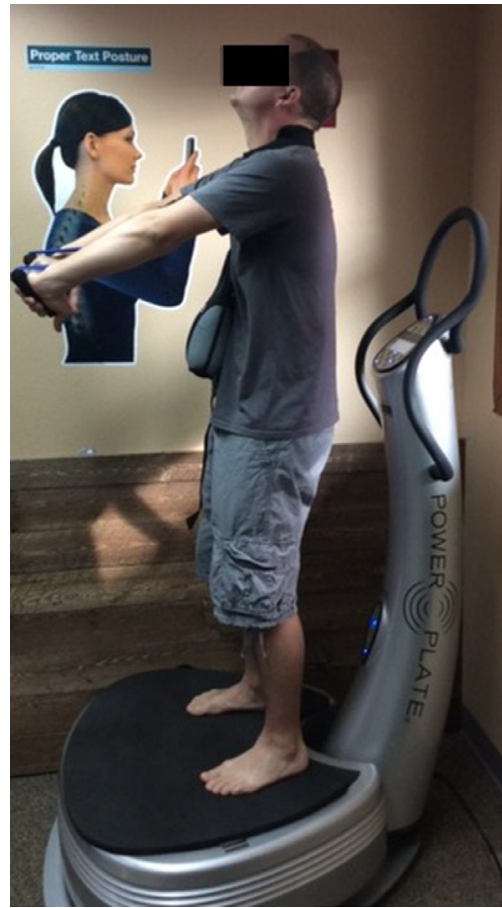

Fig. 3. Cervical extension exercises performed on the PowerPlate. 
improvement in hip and knee pain, a 70\% improvement in energy levels, a 60\% improvement in neck and upper back pain, and a $50 \%$ improvement in low back pain.

The patient did not follow the initial treatment schedule of 3 times per week because of his shift work, therefore, a followup cervical radiograph was taken on 8-28-17, following 30 treatment sessions over an 18 week time period. The lateral cervical radiographic view showed a significant improvement in lordosis (C2-C7 ARA) to $-31.7^{\circ}\left(26.9^{\circ}\right.$ improvement), a reduction of AHT to $3.8 \mathrm{~mm}$, and an improved APL to $-32.5^{\circ}$ (Fig. 1).

\section{DISCUSSION}

This case demonstrates an improvement in cervical lordosis in a patient with mid-cervical kyphosis and severe degenerative changes from previous cervical spine trauma. Although clinically observed by each of the authors previously, we believe this is the first documented case of the restoration of cervical lordosis in a severely degenerated cervical spine.

Surgical approaches to the correction of cervical kyphosis include the anterior approach, posterior approach or a combination of both; however, there are varying rates of postoperative neurological deterioration, complications, revision surgery, and even mortality ${ }^{1,23)}$.

The non-surgical approach incorporating cervical extension traction as part of CBP technique has a substantial and building evidence-base including recent case reports ${ }^{24-26)}$, non-randomized clinical trials ${ }^{20,27,28)}$ and randomized clinical trials ${ }^{29-33)}$. This evidence suggests an average increase in cervical lordosis of up to $18^{\circ}$ in $10-14$ weeks with $30-40$ treatments with use of cervical extension traction as part of a multimodal rehabilitation program.

This case demonstrated a $27^{\circ}$ improvement in cervical lordosis after 30 treatments over an 18 -week period. Despite the severe degenerative changes throughout the lower cervical spine (C4-C6), the kyphotic portion had an approximate $5^{\circ}$ reduction in kyphotic alignment. Obviously the bony deformation is permanent, and this serves as a physical limitation to an ideal alignment correction, however any improvement in cervical lordosis is essential to achieve an optimal symptom reduction, functional improvement and overall health and wellbeing.

Limitations to this study are that it is a single case report, and that there was no follow-up to evaluate the stability of the lordosis correction over time. Although multiple treatments were given to the patient (cervical extension traction, extension exercises, spinal manipulation), it is presumed that most of the structural alignment improvement resulted from the extension traction procedures as the patient had received recent previous traditional chiropractic treatments, as manipulation to the spine does not routinely change structural spinal alignment ${ }^{34-36)}$, nor does exercise ${ }^{37)}$.

We suggest that future research in these methods applied to those with osteoarthritis include flexion-extension radiographs to assess pre- and post-functional changes that have been proven to occur with extension traction methods ${ }^{29}$, 33). This may prove to be a practical, non-surgical approach to treat cervical hypolordosis/kyphosis associated with cervical spondylopathy.

As a last note, it must be mentioned that ideally the restoration of the cervical lordosis should be achieved long before a substantial time period passes that nurtures the slow but continuous degenerative changes that typically occur, and which was seen to occurred in this patient; this would be considered primary prevention.

\section{Conflict of interest}

PAO is paid by CBP NonProfit for writing the manuscript. DEH teaches chiropractic rehabilitation methods used and sells products to physicians for patient care used in this manuscript.

\section{REFERENCES}

1) Han K, Lu C, Li J, et al.: Surgical treatment of cervical kyphosis. Eur Spine J, 2011, 20: 523-536. [Medline] [CrossRef]

2) Bagnall KM, Harris PF, Jones PR: A radiographic study of the human fetal spine. 1. The development of the secondary cervical curvature. J Anat, 1977, 123: 777-782. [Medline]

3) Pal GP, Sherk HH: The vertical stability of the cervical spine. Spine, 1988, 13: 447-449. [Medline] [CrossRef]

4) Benzel EC: Biomechanics of spine stabilization. 2nd ed. Park Ridge: American Association of Neurological Surgeons, 2001, pp 375-410.

5) Harrison DE, Harrison DD, Janik TJ, et al.: Comparison of axial and flexural stresses in lordosis and three buckled configurations of the cervical spine. Clin Biomech (Bristol, Avon), 2001, 16: 276-284. [Medline] [CrossRef]

6) Frost HM: Wolff's Law and bone's structural adaptations to mechanical usage: an overview for clinicians. Angle Orthod, 1994, 64: 175-188. [Medline]

7) Frost HM: A 2003 update of bone physiology and Wolff's Law for clinicians. Angle Orthod, 2004, 74: 3-15. [Medline]

8) Vernon H, Mior S: The Neck Disability Index: a study of reliability and validity. J Manipulative Physiol Ther, 1991, 14: 409-415. [Medline]

9) McHorney CA, Ware JE Jr, Raczek AE: The MOS 36-Item Short-Form Health Survey (SF-36): II. Psychometric and clinical tests of validity in measuring physical and mental health constructs. Med Care, 1993, 31: 247-263. [Medline] [CrossRef]

10) Harrison DD: Abnormal postural permutations calculated as rotations and translations from an ideal normal upright static posture. In: Sweere JJ ed. Chiropractic family practice. Gaithersburg: Aspen Publishers, 1992, chap 6-1, pp 1-22.

11) Harrison DE, Harrison DD, Cailliet R, et al.: Cobb method or Harrison posterior tangent method: which to choose for lateral cervical radiographic analysis Spine, 2000, 25: 2072-2078. [Medline] [CrossRef]

12) Harrison DE, Holland B, Harrison DD, et al.: Further reliability analysis of the Harrison radiographic line-drawing methods: crossed ICCs for lateral posterior 
tangents and modified Risser-Ferguson method on AP views. J Manipulative Physiol Ther, 2002, 25: 93-98. [Medline] [CrossRef]

13) Harrison DE, Harrison DD, Colloca CJ, et al.: Repeatability over time of posture, radiograph positioning, and radiograph line drawing: an analysis of six control groups. J Manipulative Physiol Ther, 2003, 26: 87-98. [Medline] [CrossRef]

14) Harrison DD, Harrison DE, Janik TJ, et al.: Modeling of the sagittal cervical spine as a method to discriminate hypolordosis: results of elliptical and circular modeling in 72 asymptomatic subjects, 52 acute neck pain subjects, and 70 chronic neck pain subjects. Spine, 2004, 29: 2485-2492. [Medline] [CrossRef]

15) McAviney J, Schulz D, Bock R, et al.: Determining the relationship between cervical lordosis and neck complaints. J Manipulative Physiol Ther, 2005, 28: 187-193. [Medline] [CrossRef]

16) Harrison DD, Janik TJ, Troyanovich SJ, et al.: Comparisons of lordotic cervical spine curvatures to a theoretical ideal model of the static sagittal cervical spine. Spine, 1996, 21: 667-675. [Medline] [CrossRef]

17) Harrison DD, Janik TJ, Harrison GR, et al.: Chiropractic biophysics technique: a linear algebra approach to posture in chiropractic. J Manipulative Physiol Ther, 1996, 19: 525-535. [Medline]

18) Oakley PA, Harrison DD, Harrison DE, et al.: Evidence-based protocol for structural rehabilitation of the spine and posture: review of clinical biomechanics of posture (CBP) publications. J Can Chiropr Assoc, 2005, 49: 270-296. [Medline]

19) Harrison DE, Harrison DD, Haas JW: Structural rehabilitation of the cervical spine. Evanston, WY: Harrison CBP ${ }^{\circledR}$ Seminars, Inc., 2002.

20) Harrison DE, Harrison DD, Betz JJ, et al.: Increasing the cervical lordosis with chiropractic biophysics seated combined extension-compression and transverse load cervical traction with cervical manipulation: nonrandomized clinical control trial. J Manipulative Physiol Ther, 2003, 26: 139-151. [Medline] [CrossRef]

21) Oliver MJ, Twomey LT: Extension creep in the lumbar spine. Clin Biomech (Bristol, Avon), 1995, 10: 363-368. [Medline] [CrossRef]

22) Lee DY: Analysis of muscle activation in each body segment in response to the stimulation intensity of whole-body vibration. J Phys Ther Sci, 2017, 29: 270-273. [Medline] [CrossRef]

23) Grosso MJ, Hwang R, Krishnaney AA, et al.: Complications and outcomes for surgical approaches to cervical kyphosis. J Spinal Disord Tech, 2015, 28: E385E393. [Medline] [CrossRef]

24) Wickstrom BM, Oakley PA, Harrison DE: Non-surgical relief of cervical radiculopathy through reduction of forward head posture and restoration of cervical lordosis: a case report. J Phys Ther Sci, 2017, 29: 1472-1474. [Medline] [CrossRef]

25) Fedorchuk C, Lightstone DF, McCoy M, et al.: Increased telomere length and improvements in dysautonomia, quality of life, and neck and back pain following correction of sagittal cervical alignment using Chiropractic BioPhysics ${ }^{\circledR}$ technique: a case study. J Mol Genet Med, 2017, 11: 1-5.

26) Oakley PA, Harrison DE: Restoration of barefoot gait in a 75-year old female with cervical spondylotic myelopathy: A case report utilizing chiropractic biophysics $\left(\mathrm{CBP}^{\circledR}\right)$ technique. Chiropr J Aust, 2017, 45: 16-27.

27) Harrison DE, Cailliet R, Harrison DD, et al.: A new 3-point bending traction method for restoring cervical lordosis and cervical manipulation: a nonrandomized clinical controlled trial. Arch Phys Med Rehabil, 2002, 83: 447-453. [Medline] [CrossRef]

28) Harrison DD, Jackson BL, Troyanovich S, et al.: The efficacy of cervical extension-compression traction combined with diversified manipulation and drop table adjustments in the rehabilitation of cervical lordosis: a pilot study. J Manipulative Physiol Ther, 1994, 17: 454-464. [Medline]

29) Moustafa IM, Diab AA, Hegazy FA, et al.: Does rehabilitation of cervical lordosis influence sagittal cervical spine flexion extension kinematics in cervical spondylotic radiculopathy subjects? J Back Musculoskeletal Rehabil, 2017, 30: 937-941. [Medline] [CrossRef]

30) Moustafa IM, Diab AA, Taha S, et al.: Addition of a sagittal cervical posture corrective orthotic device to a multimodal rehabilitation program improves shortand long-term outcomes in patients with discogenic cervical radiculopathy. Arch Phys Med Rehabil, 2016, 97: 2034-2044. [Medline] [CrossRef]

31) Moustafa IM, Diab AA, Harrison DE: The effect of normalizing the sagittal cervical configuration on dizziness, neck pain, and cervicocephalic kinesthetic sensibility: a 1-year randomized controlled study. Eur J Phys Rehabil Med, 2017, 53: 57-71. [Medline]

32) Moustafa IM, Diab AA, Harrison DE: Does improvement towards a normal cervical sagittal configuration aid in the management of lumbosacral radiculopathy: A randomized controlled trial. Proceedings from the 13th biennial congress of the World Federation of Chiropractic, Athens, Greece, May 13-16, 2015, $p$ 138.

33) Moustafa IM, Diab AM, Ahmed A, et al.: The efficacy of cervical lordosis rehabilitation for nerve root function, pain, and segmental motion in cervical spondylotic radiculopathy. Physiotherapy, 2011, 97: S846-S847.

34) Plaugher G, Cremata EE, Phillips RB: A retrospective consecutive case analysis of pretreatment and comparative static radiological parameters following chiropractic adjustments. J Manipulative Physiol Ther, 1990, 13: 498-506. [Medline]

35) Hurwitz EL, Aker PD, Adams AH, et al.: Manipulation and mobilization of the cervical spine. A systematic review of the literature. Spine, 1996, 21: 1746-1759, discussion 1759-1760. [Medline] [CrossRef]

36) Shilton M, Branney J, de Vries BP, et al.: Does cervical lordosis change after spinal manipulation for non-specific neck pain? A prospective cohort study. Chiropr Man Therap, 2015, 23: 33. [Medline] [CrossRef]

37) Hrysomallis C, Goodman C: A review of resistance exercise and posture realignment. J Strength Cond Res, 2001, 15: 385-390. [Medline] 